This item was submitted to Loughborough's Research Repository by the author.

Items in Figshare are protected by copyright, with all rights reserved, unless otherwise indicated.

\title{
Qatar, global sport and the 2022 FIFA World Cup
}

PLEASE CITE THE PUBLISHED VERSION

http://www.palgrave.com/products/title.aspx?pid=705076

\section{PUBLISHER}

Palgrave Macmillan @ Selection and editorial matter Jonathan Grix @ Individual Chapters their respective authors

\section{VERSION}

AM (Accepted Manuscript)

\section{LICENCE}

CC BY-NC-ND 4.0

\section{REPOSITORY RECORD}

Brannagan, Paul M., and Richard Giulianotti. 2019. "Qatar, Global Sport and the 2022 FIFA World Cup". figshare. https://hdl.handle.net/2134/14576. 
This item was submitted to Loughborough's Institutional Repository (https://dspace.lboro.ac.uk/) by the author and is made available under the following Creative Commons Licence conditions.

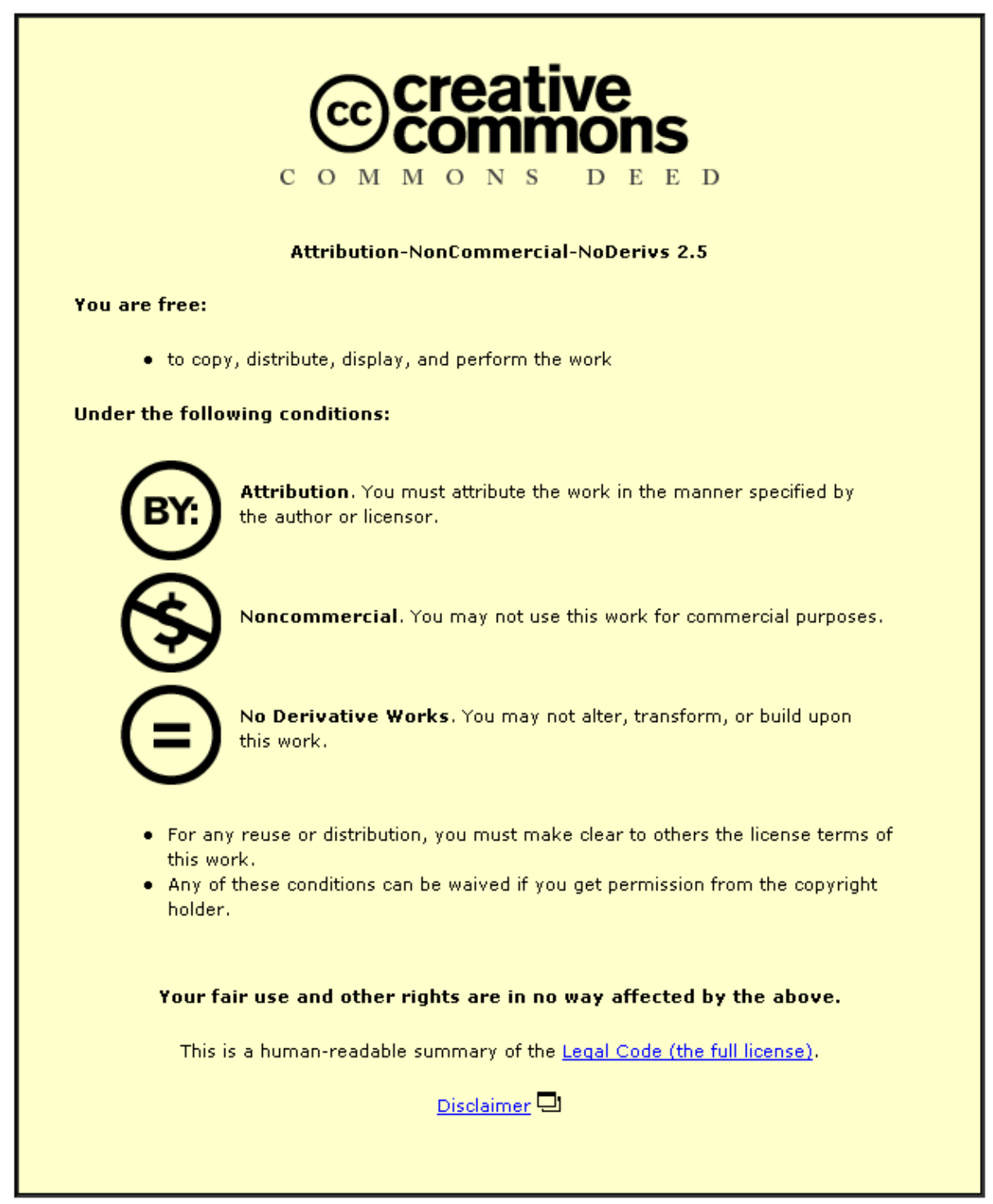

For the full text of this licence, please go to: http://creativecommons.org/licenses/by-nc-nd/2.5/ 


\title{
Chapter 14: Qatar, Global Sport, and the 2022 FIFA World Cup
}

\author{
Paul Michael Brannagan and Richard Giulianotti
}

\section{(ORIGINAL MANUSCRIPT)}

This is the Author's Original Manuscript in its final and definitive form. The Version of Record can be found via the following reference:

Brannagan, P.M. and Giulianotti, R. (2014) Qatar, Global Sport, and the 2022 FIFA World Cup. In Grix, J. (ed.), Leveraging Legacies from Sports Mega-Events, Basingstoke: Palgrave.

\section{Introduction}

In 2010 the Fèdèration Internationale de Football Association (FIFA) astounded the world when it bestowed upon the small Persian Gulf State of Qatar the opportunity to host the 2022 World Cup finals. This decision added to Qatar's desire to become a global centre for sport excellence. In what follows, we offer an introductory analysis of the state's engagement with global sports. The need for such an extract is indispensable, as, to date, there is a dearth of academic research on sport in Qatar; hence, this chapter aims to contribute substantially towards filling that gap. ${ }^{1}$

We argue that Qatar's sport engagement, primarily for promoting the nation, is focused on three foremost themes: health and well-being, progress and modernization; and peace and security. In each of these areas, we contend that sport plays a substantial role within Qatar's overarching 'soft power' strategy.

The concept of soft power, introduced by the political scientist Joseph Nye, refers to 'the ability to affect others to obtain the outcomes one wants through attraction rather than coercion or payment' (Nye 2008: 94). Foremost to this perspective is that cultural forms of power have become progressively significant for states to preserve and extend their international influence, attractiveness and prestige (ibid.). National governments draw on cultural forms such as sport, as integral aspects of their 'soft power strategies', in particular through hosting the Olympics or World Cup finals (Grix and Houlihan 2013). Such events have 
an 'unrivalled capacity to capture the attention of huge numbers of people', and accordingly may be utilized to have a potentially momentous impact on the host's international profile (Whitelegg 2000: 802). For Qatar, we argue that soft power is a critical strategy for international relations, as the state wields limited 'hard power'. Although Qatar receives a level of attention from U.S. foreign policy, independently, the state has a distinct lack of military or diplomatic capabilities, despite its oil-based wealth. Nonetheless, as Qatar has recently demonstrated, exercising a soft power strategy, within sport or elsewhere, inevitably carries some risks; here we introduce the concept of 'soft disempowerment' to refer to the other side of a soft power strategy; that is, the loss of influence, attractiveness and prestige, in absolute or relative terms, which a state may experience in the international context.

Our discussion is organized into four sections: first, we offer key background details on Qatar and its involvement in global sport; second, we explore the three broad themes relating to Qatar's sport engagement; third, we introduce and elaborate on the concept of 'soft disempowerment' within a Qatari context; and finally we offer some concluding thoughts on the lead-up to the 2022 World Cup finals. Our analysis is based in part on qualitative interviews which were conducted in 2012 with leading officials from the Qatar 2022 Supreme Committee (Q22SC), the Aspire Academy of Sporting Excellence (Aspire), and the International Centre for Sports Security (ICSS). ${ }^{1}$

\section{The State of Qatar and Global Sport}

Qatar is a sovereign Arab state, located in the Persian Gulf peninsula, which gained full independence from the UK in 1971. An absolute monarchy, ruled by the Al-Thani family since the mid-19th century, Qatar has a population of just over 250,000 Qatari citizens, and an expatriate workforce of approximately 1.5 million, employed predominantly in the construction industry. Economically, Qatar is the globe's third largest oil producer, and one of the wealthiest nations worldwide: in 2012, Qatar's GDP per capita (citizens) stood at approximately US $\$ 100,889$ compared to approximately US $\$ 51,704$ for the United States (IMF 2012). ${ }^{1}$ Much of the state's wealth is invested overseas, with Qatari backers obtaining large holdings in numerous international franchises, such as Barclays Bank, Harrods, Siemens, and BlackBerry. Internally, the state's progressive philosophy emerged in 1995, when Shaykh Hamad bin Khalifa al-Thani, the Emir of Qatar until 2013, toppled his father from power in a peaceful coup d'état. From that point, 
Qatar underwent a rapid transformation, with the goal of modernizing the country, enhancing its international status, and improving its security and competitiveness. 'Education City', for example, looks to allow Qatari citizens the competitive opportunity of a modern 'world-class' educational system; and the hosting of numerous conferences around climate-change and safety adds to a state-led strategy to put Qatar on the map by raising international awareness of its contribution towards confronting contemporary global concerns.

Global sport also plays a significant role here. Annually, the state welcomes the ATP and WTA Tennis Tournaments, and the FIM Motor Racing Championships. Intermittently, Qatar has also looked to host/acquire numerous sporting tournaments (Table 1).

Table 1: Qatar's recent acquisition of sports tournaments

\begin{tabular}{|c|c|}
\hline Tournament & $\underline{\text { Year }}$ \\
\hline West Asian Games - (hosted) & 2005 \\
\hline Asian Games - (hosted) & 2006 \\
\hline Asian Indoor Athletics Championships - (hosted) & 2008 \\
\hline FIVB Club World Championships - (hosted) & 2009 \\
\hline IAAF World Indoor Championships - (hosted) & 2010 \\
\hline Asian Football Cup - (hosted) & 2011 \\
\hline Arab Games - (hosted) & 2011 \\
\hline IHF Handball World Championships - (hosting) & 2015 \\
\hline $\begin{array}{c}\text { UCI Road Cycling World Championships - } \\
\text { (hosting) }\end{array}$ & 2016 \\
\hline $\begin{array}{l}\text { FIG Artistic World Gymnastics Championships } \\
\qquad- \text { (hosting) }\end{array}$ & 2018 \\
\hline Summer Olympic Games - (bid unsuccessful) & 2020 \\
\hline FIFA World Cup - (hosting) & 2022 \\
\hline
\end{tabular}

Furthermore, the Qatar Sport Investment group has been particularly active, with major acquisitions including the London 2012 Olympic Village, European football clubs Paris Saint-Germain and R.C.D. Mallorca, whilst also securing the original Qatar Foundation-F.C. Barcelona sponsorship deal. 
In addition, the state widely invests in sporting leagues and infrastructure. The Aspire complex, for example, originally designed for the 2006 Asian Games, is home to the 'Aspire Academy of Sporting Excellence', the Academy's 'Football Dreams Programme', and 'Aspetar' - the only FIFA medical centre of excellence in the Middle East. Incorporating two five-star hotels, a 50,000 seat stadium, an Olympic swimming pool, and state-of-the-art sports science labs, the complex attempts to add to Qatar's desire to 'rise as a global player through creative focus and development of new talent infused with world class talent' (Campbell 2010: 50).

While the Academy is occupied with development, world-class athletes are predominantly found in the state's football league: the 'Qatar Stars League'. Notable acquisitions here have included Frank de Boar, Gabriel Batistuta, Raúl González, and Pep Guardiola. In Qatar, however, drawing on overseas talent is commonly taken further, with the naturalization of athletes serving as a desired route at the national level. When athletes do not qualify through lineage, Qatar writes migrants into its national narrative through an invented association: a re-naming according to a national blood or tribal lineage (Chiba et al. 2001). Examples here include two-time steeplechase world champion Saif Saaeed Shaheen - originally born 'Stephen Cherono' in Kenya; or the Bulgarian, Angel Popov, renamed Said Saif Asaad, who secured one of Qatar's two Olympic medals at the Sydney Games in 2000.

\section{Qatar and Global Sport: Three Key Themes}

The rationale behind Qatar's engagement with global sport - its naturalization of migrant athletes, and investment in sporting leagues and infrastructure - can be explained via three overarching themes which look to address complex internal and external state motives; in this section, we turn our attention towards uncovering the state's objectives through sport.

\section{Health and Well-Being}

According to the International Association for the Study of Obesity (2012a), Qatar has some of the worst levels of obesity worldwide amongst its adult populace, as well as some of the worst rates internationally amongst its male youth population (2012b); likewise, the International Diabetes Federation (2012) situates Qatar's diabetes rate over twenty percent higher than the world's average. This critical public health issue 
is rooted in a failure to confront the negative consequences of rapid socio-cultural changes. For example, Qataris have become overly accustomed to extravagant levels of fast-food consumption, yet exert exceptionally low levels of physical activity (Qatar National Health Strategy 2011-2016).

In response, the state has progressed towards identifying health-conscious initiatives in an attempt to deal with these problems. In this context, the leadership view sport as 'the perfect investment into creating a healthier country' (Interview 1)1. Such an investment is built on the premise that: 'if the state can get sport and the whole notion of sport and culture developed here, one would hope that that actually starts to inspire a lot of the younger population to start to become much more physically active......which it is hoped will have a positive impact on a lot of the health issues they face such as diabetes, etc.' (Interview 2). ${ }^{1}$ Of course, we should arguably be somewhat sceptical of the state's success here due to the fact that little evidence exists to suggest any correlation between hosting mega-events and increased sports participation (see Weed, chapter 4, in this volume).

Driving this desire to implement a long-term sporting culture is the government-funded project of Aspire, and, most significantly, the complex's daily-run after-school-programme, the 'Multi-Skills Development Centre'. The focus here is to persuade 6-12 year old girls and boys to engage with sport and physical activity on a daily basis. To Qatari authorities, this is seen as vital, as implementing a sporting culture from a young age into a youth culture that is dominated by an affluent taste for western movies and videogames, is understood to be a crucial state measure for encouraging physical activity into the future fabric of Qatari society.

In the short-term, the Aspire complex also looks to provide a number of sport programs aimed towards implementing physical activity into the current habitus of the Qatari people. At the hub of all initiatives is 'Aspire Active's' daily run 'community health programme'. Attracting mainly men, the programme sees hundreds of local and expatriate adults each day partaking in various fitness regimes. The programme also provides the state's population with nutritional and health education; the overall goal is to provide a 'holistic approach to a healthy lifestyle' (Interview 1). 
Thus, the policy of promoting a sporting culture is closely tied to challenging the lack of physical activity, and to improve health and well-being. However, we may also view these health-based initiatives as part of the state's wider soft power strategy in two broad ways. First, there is the goal of being the first Gulf State to tackle successfully the challenge of obesity and diabetes, with sport playing a fundamental role in this regard. Second, in looking to go one step further, there is the desire to become internationally recognized as the world-leading centre for sporting expertise - most specifically through attaining world-class personnel in the fields of sport medicine and sports development; yet without the home-grown elite sporting success that tends to accompany such expertise. The result has arguably been an increasing awareness of Qatar's commitment to sporting excellence. Aspire's facilities, for example, which attract a plethora of international athletes and professional teams each year, have received high praise from members of the sporting community; indeed, Sir Alex Ferguson has previously declared Aspire's facilities 'without question the best I have ever seen.'

\section{Progress and Modernization}

The purpose of the second theme, 'progress and modernization', is the attempt to debunk specific negative, 'orientalist' images that may be held about Qatar and the 'East' in general at the international level (cf. Said 1977). Western-based orientalist stereotypes have tended to portray Arab peoples as irrational, unreasonable, lazy and lacking a sense of responsibility (Amara, 2005). Hence, successful engagement with, and leadership of, global sport is seen by Qatar as an effective mechanism for promoting better understandings of Arab and Eastern cultures. In the broader sense, sport has the ability to confront negative images by presenting the nation as modern, progressive and considerate. Other states, for example, Germany, have used sport and sport mega-events to challenge successfully long-held stereotypes (see Grix in this volume).

The desire to use sport to such an extent was highlighted during our interview with an official within the Q22SC; he informed us that, in hosting the world's largest mega-event, Qatar aims to 'create better understandings between the East and the West - just like the prejudice and misconception from the West about the Middle East'. Most specifically, Qatari authorities aim to use the tournament to demonstrate the 
state's capacity for progress and modernization. Furthermore, Qatar's hosting of the tournament has soft power impacts for the region. As our QSC22 official stated: 'we want to show people that we... and that the [Persian Gulf] region in general...is capable of handling such a massive responsibility.'

One way the Qataris look to portray such capability is through the carefully-managed construction of the 2022 World Cup stadiums. Designed by the world's leading architects, in blending the old and the new, such stadiums act as a shrine to the state's progressive objectives. The Al-Wakrah stadium, designed by Aecom, for example, attempts to weave together Qatar's past with its progressive vision for the future. Such architecture, and others like it, acts as a 'dramatic symbol of change', exerting notions of modernity and national ambition similar to additional sports-led nation/city-branding projects: Beijing, Tokyo and Seoul, etc. (Mangan 2011: 2232).

The hosting of major sport conferences is an additional sport-based soft power initiative. The annual Doha GOALS Forum, for example, attracts world-leading athletes, industry-professionals, academics and students from across the world; and the yearly ICSS 'Securing Sport' conference which accommodates over 400 of the world's key stakeholders from the sport and security sectors with the fundamental aspiration to safeguard sport's regional and international integrity.

This latter point demonstrates how Qatar similarly looks to use global sport to be seen as a pioneering microstate: through the desire to be regarded as considerate towards others, leading, in many cases, to reciprocity, as the international community may show gratitude in the form of cooperation and support (Vuving 2009). Indeed, a further aim in hosting the 2022 finals is to 'open the horizons for countries who are of a similar nature in terms of size', so that they may think, 'hey, if Qatar are able to do it, then we can do it as well' (Interview 3)1'. The legacy plans for the World Cup finals include recycling stadiums to build twenty-two in various developing nations. Such a commitment towards assisting developing nations in a meaningful way was continuously repeated by a Q2022 official, who suggested that the state wanted the 2022 finals to benefit other nations as well as Qatar itself. 
The third theme associated with Qatar's involvement in sport centres on peace and security. An important point here relates to the contemporary problems across the Middle East. We were informed that one of the 'main goals' in securing the 2022 finals was to target the vast majority of Westerners who lack a good understanding of the Persian Gulf. A critical aim here is to target those who are unable to differentiate Gaza or Baghdad from Doha or Abu Dhabi. As our Q22SC official put it, the Qatari authorities 'felt that the World Cup was an opportunity for a lot of people who are going to be visiting here, where the spotlight is going to be shown on us...that we say Qatar is nothing like some places you would see on the news.' As a soft power strategy, the Qatari authorities seek to use global sport to project the nation as one committed to peaceful ideals and values (cf. Vuving 2009).

The ICSS's wish to be committed towards international sports security, safety and integrity can be listed here. Housing sports and security personnel from across the globe, the ICSS, through conducting research and offering 'best-practice' initiatives, looks 'to become a global and international centre for sport security with a truly international focus' (Interview 1). Most significantly, the organization is presented as a vehicle for demonstrating Qatar's commitment to the universal values of peace through its desire to assist and lead the way in ensuring the 'safety, security and integrity in sport for the benefit of all humankind' (Interview 2).

Associating Qatar with peaceful, safe and security-conscious notions strongly adds to one of the state's wider objectives: the development of a powerful tourism industry. In-fact, according to the Q22SC, sport's role is highly significant in the drive to extend the state's profile at different levels. Consequently, global sport, in raising the profile of the state, is intended to function as a mechanism for attracting and retaining tourists in a rapidly globalising marketplace. Indeed, for Qatari authorities, the World Cup finals' role in raising awareness of the state is unrivalled: as put by the Q22SC, the acquisition of the tournament alone has 'catapulted us maybe 100 years in terms of profile, in terms of [the wider world] knowing who Qatar is, in terms of knowing where Qatar is'. 
A further point to be borne in mind is that any international activity by a nation-state which seeks to develop or extend soft power carries with it some reputational risk (see Grix, introduction to this volume). Indeed, where there is the pursuit of soft power there is always the potential for soft disempowerment, as nations may disturb, offend or alienate other nations, thereby leading to a loss of attractiveness and influence.

In the case of Qatar and sport, this soft disempowerment has been most acutely witnessed through international responses to human rights and organizational issues. For example, in the build-up to the 2022 World Cup finals, there has been substantial criticism from the international media, trade union organizations, and some football officials on how migrant workers (particularly South Asians) are treated in the Qatari construction industry; the most chastening reports point to high death tolls and widespread abuse of workers. ${ }^{1}$ Other criticisms have centred on the timing of the tournament, with many stakeholders advocating the need for a winter World Cup in order to avoid very high summer temperatures. There has also been concern form the international community regarding Qatar's controversial anti-gay legislation ahead of the tournament. Such incidents remind us that any sport-based soft power strategy carries with it reputational risks, as the nation is exposed more fully to international scrutiny, particularly from civil rights groups and liberal media (cf. Chalip 2005).

\section{Concluding Comments}

In this chapter we have explored the political rationale behind Qatar's hosting of the 2022 football and wider engagement with global sport. We argue that three main themes are relevant to Qatar's soft power strategy: health and well-being, progress and modernization, and peace and security. Global sport is thus

intended to advance Qatar's international appeal and influence by highlighting its modern accomplishments in regard to science and technology, the establishment of a safe and secure environment, warmth and cooperation (of what, the state?!), as well as the state's contribution and foresight in opening up new opportunities for others. 
Of course, these goals are not unique to Qatar: many governments have sought to use sport in order to reshape international perceptions, and to promote a positive national image. Subsequently, we agree with Amara (2005) that global sport is being used by Qatari authorities in order to reposition the state on the world map. However, we would argue that the success of such repositioning depends highly on how effectively the state can manage and minimize its soft disempowerment. Internally, this relates to how effective sport and physical activity might be when utilized in the fight against obesity and diabetes. Externally, reputational risks will most certainly revolve around the treatment of expatriate workers, particularly those employed in the construction industry leading up to the 2022 finals.

\section{References}

Amara, M., (2005). 2006 Qatar Asian Games: A ‘Modernization’ Project from Above? Sport in Society, Culture, Commerce, Media, Politics, 8:3, pp. 493-514.

Campbell, R., (2010). Staging globalization for national projects: Global sport markets and elite athletic transnational labour in Qatar. International Review for the Sociology of Sport, 46(1), pp.45-60.

Chalip, L., Marketing, media, and place promotion. In J. Higham. (2005). (Ed.), Sport tourism destinations: Issues, opportunities and analysis. Oxford: Elsevier

Chiba. N., Ebihara, O., \& S. Morino. (2001). Globalization, naturalization and identity: The case of borderless elite athletes in Japan. International Review for the Sociology of Sport 36:2: 203-221.

Grix, J., (2013). Sports politics and the Olympics, Political Studies Review, 11:1, pp. 15-25.

Grix J., \& Houlihan, B., (2013). Sports Mega-Events as part of a Nation's Soft Power Strategy: The Cases of Germany (2006) and the UK (2012). The British Journal of Politics and International Relations, published online i-first: doi: 10.1111/1467-856X.12017.

International Association for the Study of Obesity., (2012a). Global Obesity Regional Top 5. Available: http://www.iaso.org/site_media/library/resource_images/Global_Obesity_Top_5_in_each_region.pdf (Accessed 17th January 2014)

International Association for the Study of Obesity., (2012b). Global Trends in Children. Available: http://www.iaso.org/site media/library/resource images/Children trends global 2012.pdf (Accessed 17th January 2014)

Mangan, J., (2011). The new Asia: global transformation, regional ascendancy, and metaphorical modernity. The International Journal of the History of Sport, 28:16, pp. 2229-2239.

Nye, J., (2008). Public Diplomacy and Soft Power. The ANNALS of the American Academy of Political and Social Science, 616:1, pp. 94-109.

Qatar National Health Strategy 2011-2016. Nutrition and Physical Activity: Project in Detail. Available: http://www.nhsq.info/strategy-goals-and-projects/preventative-healthcare/nutrition-and-physicalactivity/project-in-detail (Accessed 17th January 2014)

Said, E. (1977). Orientalism. New York: Penguin

Vuving, Alexander L. (2009) How Soft Power Works, paper presented at American Political Science Association Annual Meeting, Toronto Canada, September 3.

Whitelegg, D., (2000). Going for Gold: Atlanta's Bid for Fame. International Journal of Urban and Regional Research, 24:4, pp. 801-817. 